\title{
Desarrollo en torno a la protección de datos personales en supuestos de transferencia de cartera crediticia a entidades no supervisadas
}

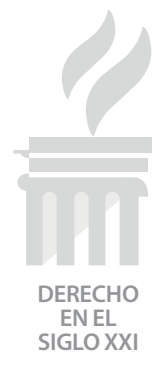

\section{Carlo Fabricio Sánchez Concha}

Abogado por la Universidad Católica San Pablo. Diplomado en Derecho del Consumidor, Publicidad Comercial y Protección del Crédito por la Universidad Católica San Pablo y el Instituto Nacional de Defensa de la Competencia y de la Protección de la Propiedad Intelectual (INDECOPI).

Alexandra Espinoza Montero

Bachiller en Derecho por la Pontificia Universidad Católica del Perú.

SUMARIO:

I. Antecedentes.

II. Sobre el Sistema Financiero.

III. ¿Cómo inicia el tratamiento de datos personales ante la contratación de un producto financiero?

IV. Transferencia de cartera crediticia.

V. ¿Qué pasa luego con la empresa no supervisada? 


\section{RESUMEN:}

El presente artículo tiene por objetivo desarrollar las contingencias y posibles soluciones en torno a la protección de datos personales de los clientes de entidades financieras cuando su crédito es transferido a una empresa no supervisada. Ello a raíz de la consulta realizada por la Superintendencia de Banca, Seguros y Administradoras Privadas de Fondos de Pensiones — SBS — a la Autoridad de Datos Personales.

Palabras clave: protección de datos, transferencia, entidad no supervisada, cartera crediticia, Superintendencia, SBS, entidad financiera.

\section{ABSTRACT: \\ This article aims to develop the contingencies and possible solutions around the protection of personal data of financial entities' clients when their credit is transferred to an unsupervised company. This as a result of the inquiry made by the Superintendency of Banking, Insurance and Pension Fund Private Management Firms — SBS — to the Personal Data Authority. \\ Keywords: Data protection, transfer, unsupervised entity, credit portfolio, Superintendency, SBS, financial entity.}

\section{ANTECEDENTES}

El 28 de junio de 2019, la Dirección General de Transparencia, Acceso a la Información Pública y Protección de Datos Personales -en adelante, la "Dirección" - publicó la Opinión Consultiva $N^{\circ}$ 39-2019-JUS/DGTAIPD —en adelante, la "Opinión Consultiva" - a partir de las consultas remitidas por la Superintendencia de Banca, Seguros y Administradoras Privadas de Fondos de Pensiones —en adelante, "SBS"—.

En la referida consulta, la SBS solicitó un pronunciamiento de la Dirección sobre la aplicación de las normas de Protección de Datos Personales en los supuestos de transferencia de cartera crediticia de una empresa supervisada por la SBS a una no supervisada, para tener actualizado el sistema integrado de registro de riesgos financieros, crediticios, comerciales y de seguros - la Central de Riesgos - a cargo de la SBS.
El problema surgió cuando las empresas supervisadas tenían la obligación de informar sobre el estado crediticio de sus clientes para que la central de riesgos se encuentre actualizada; mientras que esta obligación es limitada en el supuesto de transferencia de cartera crediticia a una empresa no supervisada, en tanto esta última alega que no cuenta con el consentimiento de los titulares de bases de datos para brindar la información sobre el nuevo historial crediticio a la SBS.

Es decir, la empresa no supervisada advierte que informar la actualización del historial crediticio de los clientes que le fueron transferidos contravendría lo dispuesto en el numeral 5 del artículo 13 de la Ley de Protección de Datos Personales ${ }^{1} y$, por ende, incurrirían en una infracción grave, tipificada en el artículo 132 del Reglamento de la Ley de Protección de Datos Personales ${ }^{2}$, exponiéndose a ser sancionados por la autoridad de protección de datos.

1. Artículo 13. Alcances sobre el tratamiento de datos personales

(...)

13.5 Los datos personales solo pueden ser objeto de tratamiento con consentimiento de su titular, salvo ley autoritativa al respecto. El consentimiento debe ser previo, informado, expreso e inequívoco.

(...).

2. Decreto Supremo Nº03-2013-JUS, Reglamento de la Ley de Protección de Datos Personales Artículo 132.- Infracciones

Las infracciones a la Ley No 29733, Ley de Protección de Datos Personales, o su Reglamento se califican como leves, graves y muy graves y se sancionan con multa de acuerdo al artículo 39 de la citada Ley.

(...) 
En este sentido, una respuesta como la brindada por las empresas no supervisadas, titulares de una cartera crediticia, generaría tres problemas:

a) Para la empresa supervisada: la obligación de mantener actualizado su reporte, de acuerdo al artículo 159 de la Ley 26702, Ley General del Sistema Financiero y del Sistema de Seguros y Orgánica de la SBS3;

b) Para el deudor: en la medida que no se reflejaría su real situación crediticia en la Central de Riesgos; $y$,

c) Para las empresas supervisadas en general: en la medida que no pueden contar con información actualizada para realizar una real evaluación del riesgo crediticio y determinar a quién y cuándo otorgar algún préstamo u otro producto financiero, entre otros.

En atención a los problemas identificados, la Dirección a partir de su opinión consultiva otorgó una respuesta tomando en consideración la aplicación de limitaciones al consentimiento dispuestos en la Ley de Protección de Datos Personales.

A raíz de ello, es inevitable preguntarnos si el pronunciamiento realizado por la Dirección es suficiente respecto al manejo en la práctica de la información crediticia de los deudores, así como las obligaciones con las que cuenta la SBS, los deberes de las entidades financieras y de aquellas empresas a las cuales les fueron transferidas las carteras crediticias, con la finalidad de no vulnerar la transparencia con la debe contar la Central de Riesgos de la SBS.

Este artículo tendrá como principal objetivo que el lector pueda entender cómo se trata la información crediticia de los deudores, calificada como datos personales, en tanto al momento de contratar con una entidad financiera, esta se encuentra en la posibilidad de transferir una cartera crediticia a una empresa no supervisada y si esta última se encontraría obligada a reportar la información de los referidos deudores sin importar su consentimiento ¿este acto, atentaría contra los derechos que protege las normas de protección de datos personales? O por el contrario, cautela y protege el interés general de las personas al mantener actualizado el registro de la Central de Riesgo, manteniendo de esta manera una información clara y transparente, tanto para las entidades financieras; así, como a los titulares de algún crédito.

Adicionalmente a ello, comentaremos sobre la interpretación realizada por la Dirección ante los problemas identificados por la SBS.

De esta forma, analizaremos lo siguiente: (a) cómo es el tratamiento de los datos personales de las personas ante una contratación con una entidad financiera, (b) qué ocurre en un supuesto de transferencia de datos a una empresa no supervisada por la SBS; y, (c) qué ocurre con la empresa no supervisada en caso le soliciten dicha información, a raíz de la opinión consultiva publicada por la Dirección.

2. Son infracciones graves:

a) No atender, impedir u obstaculizar el ejercicio de los derechos del titular de datos personales de acuerdo a lo establecido en el Título III de la Ley No 29733 y su Reglamento.

(...).

3. Artículo 159.- Obligación de suministrar la información relevante

Las empresas de los sistemas financiero y de seguros deben suministrar periódica y oportunamente, la información que se requiere para mantener actualizado el registro de que trata el artículo anterior. De contar con sistemas computarizados proporcionarán dicha información diariamente.

Toda empresa del sistema financiero antes de otorgar un crédito deberá requerir a la persona natural o jurídica que lo solicite, la información que con carácter general establezca la Superintendencia. En caso de incumplimiento no podrá otorgarse el crédito. 


\section{SOBRE EL SISTEMA FINANCIERO}

Dentro del sistema financiero podemos señalar que una de sus principales funciones es la intermediación financiera, es decir, recibir fondos de los superavitarios y colocar estos créditos a los deficitarios, intermediando. Esta actividad se realiza a través de bancos, financieras, empresas de leasing, entre otras. Esta es una actividad regulada, en tanto sólo se puede hacer lo que la ley autoriza o permite, siendo la SBS la autoridad que la regula, en la medida que se busca proteger el ahorro público.

En este sentido, estas empresas reguladas por la SBS deben cumplir en principio lo establecido en la Ley 26702, directivas, circulares y resoluciones que esta pueda emitir.

Ahora bien, en este caso nos enfocaremos en las obligaciones que tienen las entidades financieras con los usuarios o consumidores respecto al producto que contratarán, es decir, el deber de información que deben tener con estos últimos, por ejemplo, qué información le deben brindar a una persona que decide contratar una tarjeta de crédito o un préstamo personal o en general algún producto financiero ofrecido por esta entidad regulada.

Si bien es cierto, de conformidad con el Reglamento de Gestión de Conducta de Mercado del Sistema Financiero, Resolución SBS $N^{\circ}$ 3274-2017, se establecen obligaciones por parte de las entidades financieras a favor de los consumidores. Vamos a notar que el artículo 50, referido a las cláusulas generales de contratación de aprobación administrativa previa por la SBS, señala en su numeral 4 que las cláusulas que se aprueban están referidas a los derechos y obligaciones a las cuales se someterán las partes dentro de su competencia, pues no emitirán pronunciamiento sobre la aplicación de normas y disposiciones particulares emitidas por otros organismos autorizados para tal fin.

Es decir, la SBS solo supervisará aquellas cláusulas que estén relacionadas con la naturaleza del producto financiero que se ofrecerá, intereses, pagos adelantados, plazos, condiciones promocionales, entre otros.

En la medida que, en lo referido a protección de datos la competencia es de la Autoridad Nacional de Protección de Datos, es natural que las entidades financieras decidan consignar una cláusula de protección de datos fuera de estos contratos administrativamente aprobados para que los usuarios la suscriban de manera independiente para recibir, por ejemplo, publicidad de la entidad financiera, el ofrecimiento de otros productos financieros, promociones, sorteos, entre otros; pero, ¿cuál será el contenido específico de esta cláusula?

Por otro lado, en los casos en los cuales sus datos personales son imprescindibles para la ejecución contractual, no será necesario su consentimiento ${ }^{4}$.

\section{III. ¿CÓMO INICIA EL TRATAMIENTO DE DA- TOS PERSONALES ANTE LA CONTRATA- CIÓN DE UN PRODUCTO FINANCIERO?}

Los contratos suscritos entre clientes y las entidades financieras son los denominados contratos por adhesión, los cuales son definidos por el Código Civil, en el artículo 1390, como aquel a partir del cual una de las partes solo se encuentra en la

4. Ley 29733, Ley de Protección de Datos Personales

Artículo 14. Limitaciones al consentimiento para el tratamiento de datos personales

No se requiere el consentimiento del titular de datos personales, para los efectos de su tratamiento, en los siguientes casos:

(...)

5. Cuando los datos personales sean necesarios para la ejecución de una relación contractual en la que el titular de datos personales sea parte, o cuando se trate de datos personales que deriven de una relación científica o profesional del titular y sean necesarios para su desarrollo o cumplimiento. 
alternativa de aceptar o rechazar íntegramente las estipulaciones fijadas por la otra parte ${ }^{5}$.

De esta forma, dichos contratos contienen cláusulas generales de contratación, las cuales son definidas por el artículo 1392 del Código Civil, como aquellas redactadas previa y unilateralmente por una persona o entidad en forma general y abstracta, con el objeto de fijar el contenido normativo de un conjunto de futuros contratos particulares ${ }^{6}$.

En el caso que nos ocupa, la SBS se encarga de evaluar y aprobar las cláusulas que son incorporadas en los contratos firmados por los futuros clientes de las entidades financieras. De esta forma, sus cláusulas son "aprobadas por autoridad administrativa", las cuales, en atención a lo dispuesto por el artículo 1393 del Código Civil, son incorporadas a todas las ofertas que se formulen para contratar con arreglo a ellas ${ }^{7}$.

Asimismo, el numeral 2 del artículo 54 de la
Ley 29571, Código de Protección y Defensa del Consumidor —en adelante, el "Código"-, señala que es la SBS la encargada de aprobar los contratos de consumos celebrados por las empresas sometidas a su supervisión ${ }^{8}$.

De esta forma, el artículo 55 del Código dispone que la autoridad sectorial, en este caso la SBS, difunde en un lugar destacado de su portal institucional, o a través de otros medios de difusión, las cláusulas generales de contratación aprobadas administrativamente ${ }^{9}$.

Es decir, las empresas del sistema financiero tienen la obligación de presentar los contratos que suscribirán sus clientes ante la SBS para que, a su vez, este organismo pueda evaluarlas, aprobarlas y finalmente publicarlas en su portal institucional.

Ahora bien, en un primer momento, a raíz de la publicación de la Ley de Protección de Datos Personales y su Reglamento, dichos contratos

5. Decreto Legislativo 295, Código Civil

Contrato por adhesión

Artículo 1390.- El contrato es por adhesión cuando una de las partes, colocada en la alternativa de aceptar o rechazar integramente las estipulaciones fijadas por la otra parte, declara su voluntad de aceptar.

6. Cláusulas generales de contratación

Artículo 1392.- Las cláusulas generales de contratación son aquéllas redactadas previa y unilateralmente por una persona o entidad, en forma general y abstracta, con el objeto de fijar el contenido normativo de una serie indefinida de futuros contratos particulares, con elementos propios de ellos.

7. Cláusulas generales aprobadas por autoridad administrativa

Artículo 1393.- Las cláusulas generales de contratación aprobadas por la autoridad administrativa se incorporan automáticamente a todas las ofertas que se formulen para contratar con arreglo a ellas, sin perjuicio de lo dispuesto en el artículo 1395.

8. Artículo 54.- Aprobación de cláusulas generales de contratación

(...)

54.2 En el caso de los contratos de consumo celebrados por empresas sometidas a la supervisión de la Superintendencia de Banca, Seguros y Administradoras Privadas de Fondos de Pensiones, la aprobación administrativa de las cláusulas generales de contratación corresponde a dicha entidad, conforme a la ley de la materia.

(...)

9. Ley 29571, Código de Protección y Defensa del Consumidor Artículo 55.- Difusión de las cláusulas generales de contratación aprobadas por la autoridad administrativa La autoridad sectorial difunde en un lugar destacado de su portal institucional y, en su caso, a través de otros medios de difusión, las cláusulas generales de contratación aprobadas administrativamente y las cláusulas abusivas identificadas. El Indecopi mantiene enlaces en su portal institucional con las direcciones electrónicas de las autoridades sectoriales competentes en donde publiquen esa información. 
contaban con una cláusula de protección de datos personales, en aras de gatillar el consentimiento del titular de los datos personales para realizar el tratamiento de sus datos con la finalidad de ejecutar la relación contractual en la cual se veían inmersos, e incluso para que dicha información pueda ser utilizada para fines adicionales, tales como brindar publicidad y ofrecerle productos relacionados a los que contrataría.

Sin embargo, la SBS constató que aprobar dichas cláusulas, las cuales versaban sobre protección de datos personales, no era parte de sus competencias, en tanto el contenido de las cláusulas y constatar si estas se encontraban en concordancia con la normativa de datos personales le correspondía a la Dirección. Incluso, era posible que cláusulas que no seguían los criterios de la Dirección, sean erróneamente consideradas como aprobadas administrativamente, y ello sea una razón por la cual las entidades financieras señalen que dichas cláusulas no contravienen ninguna disposición normativa.

Fue por esta razón que la SBS señaló mediante Resolución SBS N³274-2017 que las cláusulas que correspondían a protección de datos personales sean remitidas a los clientes en un formato adicional al contrato otorgado por las entidades financieras, y que este no conste dentro del contrato que es aprobado administrativamente.

Es por ello que a partir del año 2017 los contratos aprobados administrativamente por la SBS no cuentan con cláusulas de protección de datos. Incluso, la Dirección cuenta con un formato recomendado de cláusula que podrá ser utilizada de referencia para que esta sea incorporada en los contratos que la necesiten.

En atención al artículo 13.5 de la Ley de Protección de Datos Personales, es obligatorio gatillar el consentimiento de las personas para poder realizar tratamiento de sus datos personales. Es incuestionable que información tal como su nombre, documento de identidad, dirección son datos personales, pero ¿acaso la información financiera lo es?

El artículo 2 de la Ley de Protección de Datos Personales, señala que serán considerados datos personales toda aquella información que identifique o haga identificable a una persona.

Ahora bien, respecto a la información sobre las deudas contraídas por una determinada persona, la Dirección publicó el Oficio N ${ }^{\circ}$ 548-2018JUS/DGTAIPD, en la cual dispone que dicha información constituye datos personales, dado que hacen referencia a actividades económicas y/o financieras de dicha persona.

Es decir, la información financiera también forma parte de aquellos datos que son materia de protección por la normativa especializada en datos personales. Por ello, la información vinculada a las empresas con las que mantenemos deudas, o nuestra calificación crediticia, serán consideradas información personal.

Dicha información es de suma importancia en tanto esta es almacenada por las entidades financieras y transferida a la SBS para poder actualizar las bases de datos de dicha entidad que contienen información sobre la solvencia patrimonial de las personas. Ello se encuentra en concordancia a los deberes de la SBS, debidamente señalados en el artículo 158 de la Ley del Sistema Financiero, el cual dispone que la información sobre los riesgos financieros y crediticios será almacenada en un sistema integrado denominado "Central de Riesgos" a cargo de esta entidad ${ }^{10}$.

Cabe señalar que para transferir dicha infor-

10. Artículo 158.- Organización de la Central de Riesgos e información que contendrá.

La Superintendencia tendrá a su cargo un sistema integrado de registro de riesgos financieros, crediticios, comerciales y de seguros denominado "Central de Riesgos", el mismo que contará con información consolidada y clasificada sobre los deudores de las empresas. 
mación, las entidades financieras no están obligadas a solicitar el consentimiento de sus clientes, dado que se aplica el artículo 14.3 de la Ley de Protección de Datos Personales, el cual señala que no se requerirá el consentimiento de las personas cuando se trate de información relacionada a la solvencia patrimonial y de crédito conforme a ley, de los titulares de los datos personales.

En el presente caso, es la Ley del Sistema Financiero la que dispone la obligación de remitir dicha información a la SBS, la cual se relaciona a la solvencia patrimonial de las personas.

Dicha interpretación se encuentra en concordancia con el Oficio $N^{\circ}$ 320-2017-JUS/DGTAIPD, en la cual la Dirección responde la consulta relacionada a la transferencia de información financiera de un cliente de una entidad financiera a centrales de información de riesgos.

Entonces, a partir de lo señalado podemos concluir que a partir de la suscripción de un contrato de adhesión con las entidades financieras, este activa el consentimiento de sus clientes, de ser necesario, en un documento adicional para tratar sus datos para la ejecución contractual, e incluso para finalidades adicionales a estas. Asimismo, toda aquella información que se relaciona con la solvencia patrimonial de las personas es luego transferida a la SBS, en atención a la obligación legal que surge a partir de lo dispuesto en la Ley del Sistema Financiero.

\section{TRANSFERENCIA DE CARTERA CREDITICIA}

Ahora bien, mediante Resolución SBS N ${ }^{\circ} 1308$ 2013 se aprobó el Reglamento de Transferencia y Adquisición de Cartera Crediticia, que dejó sin efecto la Resolución SBS N 1114-99 y sus normas modificatorias y complementarias, en tanto el numeral 26 del artículo 221 de la Ley del
Sistema Financiero señala que las empresas del sistema financiero pueden celebrar contratos de compra o venta de cartera.

La Resolución SBS N 1308-2013, en su artículo 12 señala que las empresas que transfieran carteras mediante una operación que implique la baja de cartera de créditos de acuerdo a las normas contables establecidas en el Manual de Contabilidad deberán seguir algunas reglas.

En el caso de empresas vinculadas - personas naturales o jurídicas que sean de propiedad de la entidad financiera, tomando en cuenta los porcentajes que la Ley del Sistema Financiero establece- deberán continuar remitiendo un reporte crediticio de deudores por cada lote de operación de transferencia, siendo este reporte de manera mensual.

En caso de transferencia a empresas no vinculadas, también se exige la obligación por parte del transferente a reportar a los deudores; asimismo, obliga a los transferentes a enviar a la SBS información actualizada cada vez que los deudores soliciten su actualización siempre que este último acredite el pago parcial o total de su deuda.

Ahora, el artículo 12 de la Resolución SBS No 1308-2013, adicionalmente establece que en caso de empresas supervisadas, adquirentes de carteras crediticias, estas deberán remitir de manera directa a las SBS el Reporte Crediticio de Deudores.

Nótese que la referida resolución de la SBS hace referencia a empresas vinculadas, no vinculadas y establece obligación a las empresas supervisadas, por lo que cabe la posibilidad que los adquirentes no sean entidades supervisadas, esto es, fuera del ámbito de competencia de la SBS, en estos supuestos ila empresa adquirente no

Toda institución gremial que cuente con la infraestructura necesaria correspondiente podrá tener acceso a esta Central, celebrando el correspondiente convenio con la Superintendencia.

Se registrará en la Central de Riesgos, los riesgos por endeudamientos financieros y crediticios en el país y en el exterior, los riesgos comerciales en el país, los riesgos vinculados con el seguro de crédito y otros riesgos de seguro, dentro de los límites que determine la Superintendencia. 
supervisada, está obligada a informar a la SBS el Reporte Crediticio de Deudores?

En primera instancia, en la medida que es obligación legal mantener el registro de reporte crediticio de la SBS actualizado, la respuesta sería afirmativa; sin embargo, las empresas no supervisadas señalan que en la medida que no cuentan con el consentimiento de los titulares de datos personales se ven impedidos de brindar esta información para que el referido registro se encuentre actualizado, por lo que de hacerlo, serian pasibles de denuncias y sanciones por parte de la Autoridad Nacional de Protección de Datos, lo cual explicaremos a mayor detalle en el siguiente punto.

\section{V. ¿QUÉ PASA LUEGO CON LA EMPRESA NO SUPERVISADA?}

Entonces, luego de que es realizada una transferencia de cartera crediticia a una empresa no supervisada por la SBS, se presentan los tres problemas señalados en el acápite de antecedentes.

La opinión consultiva propone la siguiente interpretación:

a) Respecto al primer problema, la Dirección señala que, en atención al principio de calidad, la SBS tiene el deber de mantener actualizadas sus bases de datos ${ }^{11}$. Asimismo, se señala que según lo dispuesto en el artículo 14.1 de la Ley de Protección de Datos Personales, no será necesario que se solicite el consentimiento de los titulares de datos personales cuando estos son solicitados en atención al ejercicio de las funciones de las entidades públicas en el ámbito de sus competencias ${ }^{12}$.

b) Respecto al segundo problema, señala que en tanto la información es necesaria para que se cuente con el historial crediticio de los deudores actualizado, tampoco será necesario contar con su consentimiento en la transferencia dado que el artículo 14.3 de la Ley de Protección de Datos Personales dispone que ello no será necesario cuando se trate de datos relativos a la solvencia patrimonial y de crédito.

c) Por último, respecto al tercer problema, la Dirección precisa que existe un interés legítimo de los deudores en que la Central de Riesgos cuente con la información actualizada, es por ello que en razón del artículo 14.9 no será necesario contar con el consentimiento de los titulares en tanto la transferencia es necesaria para salvaguardar dichos intereses legítimos ${ }^{13}$.

11. Ley 29733, Ley de Protección de Datos Personales Artículo 8. Principio de calidad

Los datos personales que vayan a ser tratados deben ser veraces, exactos y, en la medida de lo posible, actualizados, necesarios, pertinentes y adecuados respecto de la finalidad para la que fueron recopilados. Deben conservarse de forma tal que se garantice su seguridad y solo por el tiempo necesario para cumplir con la finalidad del tratamiento.

12. Artículo 14. Limitaciones al consentimiento para el tratamiento de datos personales

No se requiere el consentimiento del titular de datos personales, para los efectos de su tratamiento, en los siguientes casos:

1. Cuando los datos personales se recopilen o transfieran para el ejercicio de las funciones de las entidades públicas en el ámbito de sus competencias.

(...).

13. Artículo 14. Limitaciones al consentimiento para el tratamiento de datos personales No se requiere el consentimiento del titular de datos personales, para los efectos de su tratamiento, en los siguientes casos:

(...)

9. Cuando el tratamiento de los datos personales sea necesario para salvaguardar intereses legítimos del titular de datos personales por parte del titular de datos personales o por el encargado de tratamiento de datos personales. (...). 
Si bien concordamos con la solución propuesta por la Dirección en tanto surge de una interpretación correcta y lógica respecto a la normativa sobre protección de datos personales, aún persiste un problema principal: las empresas no supervisadas no se encuentran obligadas a remitir la información solicitada por la SBS; y, las opiniones consultivas no son de obligatorio cumplimiento.

Ahora bien, sobre la obligatoriedad de las opiniones consultivas, la SBS aun así podría alegar que la excepción al consentimiento previsto en el artículo 14.3 de la Ley de Protección de Datos Personales se encuentra en el marco de lo dispuesto por el Tribunal Constitucional en reiterada jurisprudencia.

En ese sentido, la Sentencia recaída en el Expediente $\mathrm{N}^{\circ} 3700-2019-\mathrm{PHD} / \mathrm{TC}$ señala que la difusión de la información crediticia cumple con un "fin constitucionalmente legítimo", y por ello no es necesario que para su tratamiento se recabe el consentimiento de su titular, dado que se entiende "que la permisibilidad legal resulta legitimo solo y exclusivamente para la información de tipo crediticio".

Adicionalmente a ello, la misma Sentencia del Tribunal Constitucional señala que la finalidad a partir de la cual es recabada la información resulta legítima, dado que debe existir un "flujo continuo de información de riesgos crediticios en el mercado, pues solo así se puede generar confianza en el sistema financiero". Ello, en la medida que es información crucial para el otorgamiento de créditos y su consiguiente recuperación, para así conocer el comportamiento de personas jurídicas y naturales en el tiempo, y tomar decisiones adecuadas.

Pero, ¿qué ocurre si aun así las empresas no supervisadas se niegan a transferir la información solicitada por la SBS? Podrían alegar que en atención al artículo 159 de la Ley del Sistema Financiero, estas no se encuentran obligadas a cumplir con entregar la información dado que dicho artículo hace referencia específica a las empresas del sistema financiero y de seguros, siendo estas no parte de dicho giro ${ }^{14}$, aún podría persistir la negativa.

Somos de la idea que, si bien como hemos podido apreciar, hay otros artículos de la Ley de Protección de Datos Personales que exonerarían la obligación de requerir el consentimiento de los clientes de las entidades financieras que transfirieron sus carteras, existe la posibilidad que estas entidades financieras consignen cláusulas en las que incluyan el consentimiento de sus usuarios en caso su crédito sea transferido, eliminando cualquier excusa por parte de estas empresas no supervisadas; asimismo, establecer penalidades en caso incumplan con esta obligación, pues el punto referido al consentimiento ya se encontraría superado.

14. Artículo 159.- Obligación de suministrar la información relevante.

Las empresas de los sistemas financiero y de seguros deben suministrar periódica y oportunamente, la información que se requiere para mantener actualizado el registro de que trata el artículo anterior. De contar con sistemas computarizados proporcionarán dicha información diariamente.

Toda empresa del sistema financiero antes de otorgar un crédito deberá requerir a la persona natural o jurídica que lo solicite, la información que con carácter general establezca la Superintendencia. En caso de incumplimiento no podrá otorgarse el crédito. 